\title{
Progress of Microfluidics for Biology and Medicine
}

\author{
Jingdong Chen ${ }^{1}, \quad$ Di Chen ${ }^{1, *}, \quad$ Yao Xie ${ }^{1}, \quad$ Tao Yuan $^{1}, \quad$ Xiang Chen ${ }^{2}$
}

(Received 5 March 2013; accepted 25 March 2013; published online 30 March)

\begin{abstract}
Microfluidics has been considered as a potential technology to miniaturize the conventional equipments and technologies. It offers advantages in terms of small volume, low cost, short reaction time and highthroughput. The applications in biology and medicine research and related areas are almost the most extensive and profound. With the appropriate scale that matches the scales of cells, microfluidics is well positioned to contribute significantly to cell biology. Cell culture, fusion and apoptosis were successfully performed in microfluidics. Microfluidics provides unique opportunities for rare circulating tumor cells isolation and detection from the blood of patients, which furthers the discovery of cancer stem cell biomarkers and expands the understanding of the biology of metastasis. Nucleic acid amplification in microfluidics has extended to single-molecule, high-throughput and integration treatment in one chip. DNA computer which is based on the computational model of DNA biochemical reaction will come into practice from concept in the future. In addition, microfluidics offers a versatile platform for protein-protein interactions, protein crystallization and high-throughput screening. Although microfluidics is still in its infancy, its great potential has already been demonstrated and will provide novel solutions to the high-throughput applications.
\end{abstract}

Keywords: Microfluidics; Lab-on-a-chip; Droplet; High-throughput; Cell; Nucleic acid amplification

Citation: Jingdong Chen, Di Chen, Yao Xie, Tao Yuan and Xiang Chen, "Progress of Microfluidics for Biology and Medicine", Nano-Micro Lett. 5(1), 66-80 (2013). http://dx.doi.org/10.3786/nml.v5i1.p66-80

\section{Introduction}

Microfluidics is a science and technology system that processes or manipulates small amounts of fluids, using channels with dimensions of tens to hundreds of microns [1]. It offers advantages in terms of small volume, low cost, short reaction time and high-throughput. Since micro total analysis system ( $\mu$-TAS), also known as "lab-on-a-chip" was proposed in the early 1990s [2], microfluidics has been considered as a potential technology to miniaturize the conventional equipments and technologies. The early microfluidics was served as a simple means to deliver small amount of analytes to the sensor [3]. Quake et al. [4] proposed the concept of large-scale integration in microfluidics based on micropump and microvalve in 2002. It offered the potential of microfluidics in academia and industry.
With the development of microelectromechanical system (MEMS) technology, some integrated and multifunction microfluidic chips were proposed. They are significantly changing the way of processing chemical and biological analysis [5,6], cell and gene analysis [7,8], drug discovery and clinical diagnostics $[9,10]$, material synthesis $[11,12]$ and environmental monitoring $[13,14]$. Among them, the applications in biology and medicine research and related areas are almost the most extensive and profound.

In this review, we first provide the physics of microfluidics to understand the physical phenomena at the microscale. Then we introduce a summary of droplet microfluidics technology with droplet generation and manipulation and an ingenious SlipChip. Finally, we discuss recent advances of microfluidics in biology and medicine, such as cell analysis, nucleic acid analysis,

\footnotetext{
${ }^{1}$ Science and Technology on Micro/Nano Fabrication Laboratory, Research Institute of Micro/Nano Science and Technology, Shanghai Jiao Tong University, Shanghai 200240, China

${ }^{2}$ Key Laboratory for Thin Film and Microfabrication of the Ministry of Education, Research Institute of Micro/Nano Science and Technology, Shanghai Jiao Tong University, Shanghai 200240, China

*Corresponding author. E-mail: dchen@sjtu.edu.cn
} 
protein engineering and high-throughput screening.

\section{Physics of microfluidics}

The fluid flow in microfluidics shows different properties due to small scaling. Generally, the characteristic scale is from $0.1 \mu \mathrm{m}$ to $1 \mathrm{~mm}$ and it agrees well with the scale range of microhydrodynamics. Stone et al. [15] provided an overview of fluid flow in microfluidics with focus on electrokinetics, mixing and dispersion, and multiphase flows.

\section{Laminar Flow}

Laminar flow indicates the velocity of a particle in a fluid stream is not a random function of time [16]. The flow in microfluidics is almost always laminar due to the small size of microchannels. The flow regime -laminar or turbulent can be described by Reynolds number $R e$. The Reynolds number Re indicates the importance of inertia compared with viscous stresses, and is defined as [17]

$$
\operatorname{Re}=\frac{\rho u D_{h}}{\eta}
$$

where $\rho, u$ and $D_{h}$ are density, flow velocity and hydraulic diameter of the microchannel, respectively.

\section{Diffusion}

The different streams flowing in contact with each other can not mix except by diffusion due to laminar flow in microfluidics. Diffusion can be modeled by the equation $[16]$ :

$$
t=\frac{l^{2}}{2 D}
$$

where $t$ is the diffusion time of a molecule to diffuse over a distance $l$ and $D$ is the diffusion coefficient of the molecule in solution. Some recent excellent reviews on mixing in microfluidics $[18,19]$ can also be referred for further understandings.

\section{Capillary number}

Droplet microfluidics has become an increasingly popular platform for fluid flow at the microscale, since its advent in the early 2000s [20-22]. Several key dimensionless parameters can be used to analyze droplet dynamics. The capillary number $C a$ plays a key role in microfluidic droplet's formation. The capillary number is defined in terms of the continuous phase flow field that acts to deform the droplet [23],

$$
C a=\frac{\eta_{c} \nu_{c}}{\gamma}
$$

where $\eta_{c}$ is the viscosity of the continuous phase, $v_{c}$ is the velocity of the continuous phase, and $\gamma$ is the interfacial tension between the oil and water phases. The capillary number is characterized by the relative importance of viscous stresses and capillary pressure. Droplet breaks off when the capillary number is beyond a certain critical value.

\section{Weber number}

The Weber number $W e$, which compares inertia to interfacial tension, is used frequently to parametrize droplet breakup processes. The result of multiplying the Reynolds number and the capillary number gives the Weber number,

$$
W e=\operatorname{Re} \times C a
$$

The interface effect has a significant influence on flow in microfluidics due to small Weber number, comparing with flow in macroscale.

\section{Bond number}

Finally, the Bond number $B o$ characterizes the relative importance of gravity and interfacial tension, and is given by

$$
B o=\frac{\Delta \rho g w^{2}}{\gamma}
$$

where $\Delta \rho$ is the density difference between the two immiscible fluids, $g$ is the acceleration of gravity, and $w$ is the characteristic length scale. Gravity is typically negligible in droplet formation in microfluidics due to small density difference for water droplets in oil.

\section{Types of microfluidics}

Microfluidics can be divided into continuous-flow microfluidics and droplet microfluidics.

\section{Continuous-flow microfluidics}

Continuous-flow microfluidics refers to only a single phase fluid in the chip. It reduces consumption of sample and reagent, enhances analysis speed and improves reproducibility, comparing with traditional experiment. However, there are some problems to be solved. (1) In continuous-flow microfluidics, some of sample and reagent is wasted caused by the channel filled with reagent for continuous flow. So it is important to further reduce consumption of the precious sample and reagent. (2) It need more time to achieve rapid and uniform mixing due to laminar flow $[18,19]$. (3) The sample and reagent is easy to be contaminated by the channel. (4) Scaling up is a challenge as the size of devices scales almost linearly with the number of parallel experiments [24]. 


\section{Droplet microfluidics}

Droplet microfluidics deals with generation, manipulation, and applications of droplets in microfluidic devices. Unlike continuous-flow microfluidics, droplet microfluidics focuses on creating discrete droplets using immiscible phases. The droplets serve as discrete microreactors, so the reaction in each droplet can be carried out without cross-talk between samples or reagents. Droplet microfluidics also provides a platform to perform many reactions and offers greater potential in high-throughput applications.

In general, droplets are typically generated using three main generation strategies: co-flowing $[20,25]$, Tjunction [21] and flow focusing [22], as shown in Fig. 1 [26]. Droplet microfluidics is capable of generating over 1-million, monodisperse, picolitre droplets in several minutes [27], so parallel processing and experimentation can be easily achieved, and large data can be acquired efficiently. Therefore, droplet microfluidics provides a platform to perform many reactions and offers greater potential in high-throughput applications.

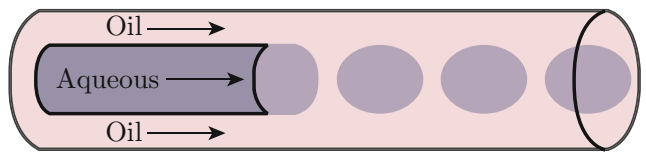

(a) Capillary

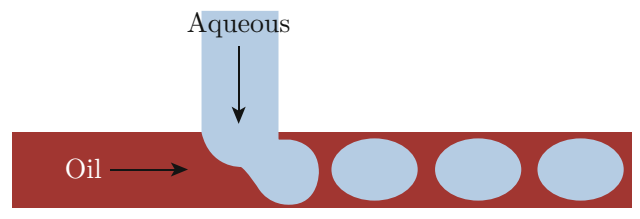

(b) T-Junction

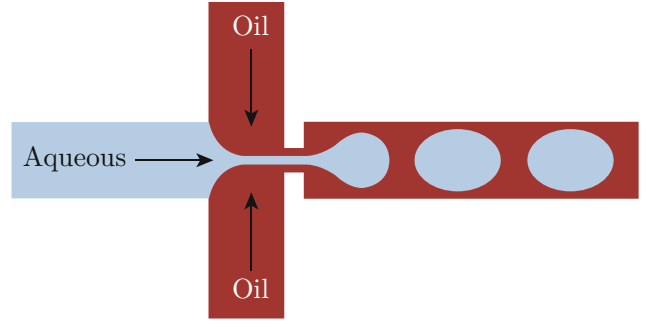

(c) Flow focusing

Fig. 1 Illustrations of the three main microfluidic strategies used for droplets generation: (a) Co-flowing in a capillary format, (b) T-junction in a planar chip format, (c) Flow focusing in a planar chip format [26].

Controlled fusion of droplets is a fundamental operation unit for the droplets to be used as microreactors. To initiate a reaction in a droplet, two sets of droplets are separately generated and then brought into contact and fusion. In recent years, several passive and active methods have been developed for inducing fusion between two droplets. In passive droplet fusion, modulating the channel geometry is usually used to control the location of droplet fusion [28,29], as shown in Fig. 2(a).
Aside from passive methods, active droplet fusion methods based on electric field, heating and optical tweezers have also been proposed $[30,31]$.

It is desirable not only to fuse droplets but also to fragment a droplet into two or more droplets for some microfluidic processing steps to increase the droplet production frequency, as shown in Fig. 2(b). It can be used for incubation or screening to enhance the effectiveness of droplet [32-35].

Mixing of reagents is necessary to accurately determine the starting time of a reaction. In continuous flow microfluidic systems, mixing is achieved by diffusion because of laminar flow. It is commonly a very slow process even inside droplets. Basically, there are also passive and active methods in droplet mixing like droplet fusion. A classic passive way is using turns and bends in a channel to introduce chaotic advection and enhance the internal mixing within droplets [18,36-38]. In a straight channel, two equal recirculation flows are generated in each half of the droplet. As the droplet moves along a winding channel, the two halves of the droplet experience unequal recirculating flows due to the shear interaction of the channel wall, as shown in Fig. 2(c). Active mixing is categorized with respect to the type of external perturbation energy: electrokinetic, dielectrophoretic, electrowetting and ultrasound. A detailed review can be seen in the paper by Capretto et al. [19].

In order to store droplets for up to several hours or even days or maximize the number of drops in the microscope field of view, it is necessary to position droplets in an array. Huebner et al. [39] presented a device that enables local storage and release of picolitersized water-in-oil droplets without using electrical or optical actuators, as shown in Fig. 2(d). The device consists of hydrodynamic droplet trapping structures array. The trapped droplets can be recovered from the microfluidic array for further processing. Then they proposed a microfluidic chip for the efficient trapping of droplet pairs [40]. The trapping structure can trap droplets from two directions. So a surfactant bilayer is formed between the trapped droplets. It provides a high throughput and effective platform for the observation and detection of diffusion across such bilayer. Multiple-droplet clustering in a controlled manner has been realized with the guiding tracks [41].

Some researchers also proposed other methods to generate droplets. Recently, the team in the University of Chicago pioneered an ingenious method (SlipChip) to perform microfluidic chip without external pumps, valves and other equipment for operation [42-44]. The working principle of the SlipChip is illustrated in Fig. 3. The system consists of two glass plates with arrays of wells (reservoirs) and ducts (fluidic pathways) on its surface. The wells and ducts of one plate are complementary in pattern to that of other plate. So they can 

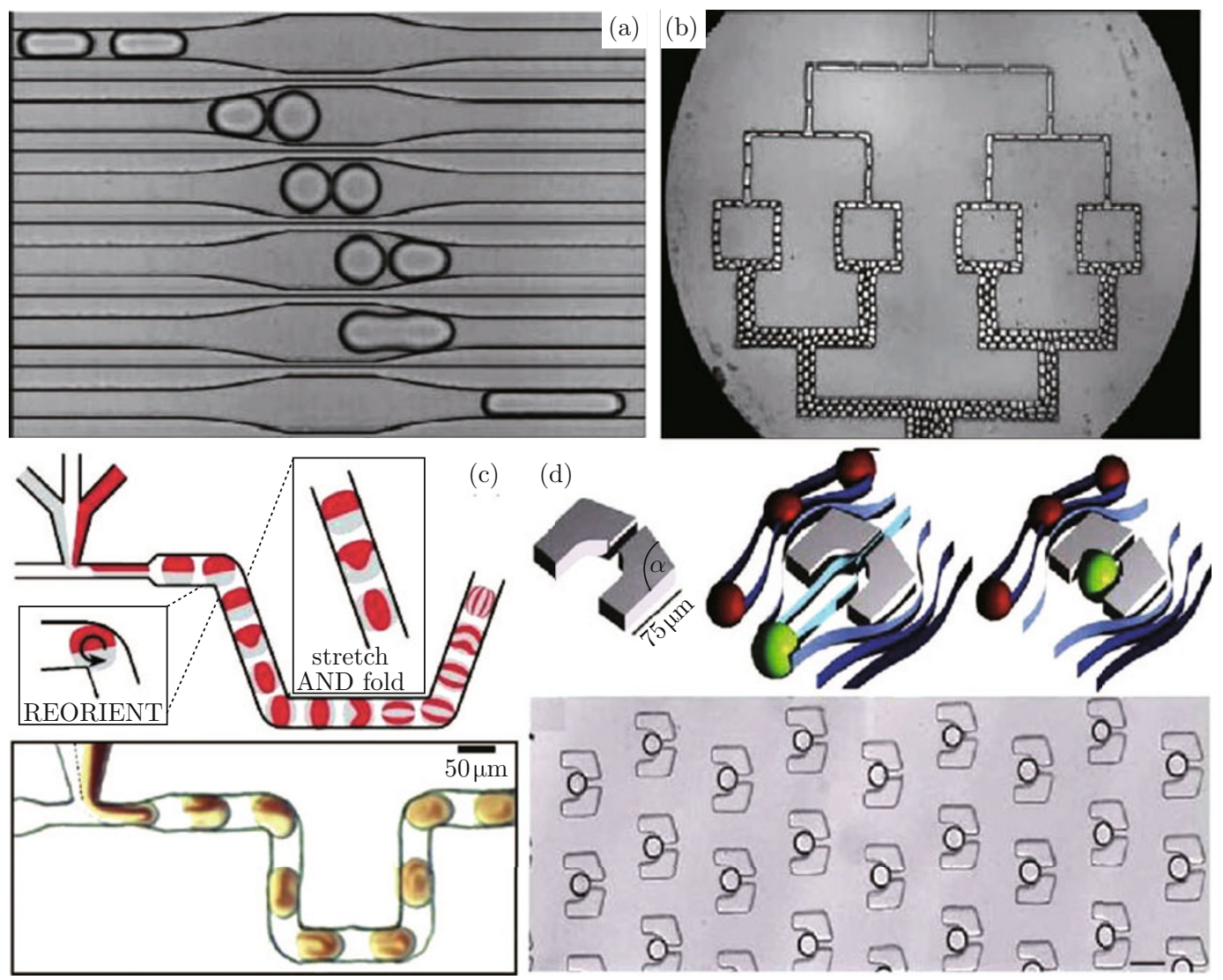

Fig. 2 Droplet manipulation (a) Passive fusion by Bremond et al. [28]. (b) T-junctions droplets splitting by Link et al [32]. (c) Mixing in microdroplets flowing in a winding microchannel [37]. (d) Principle and Results of droplet trapping arrays [39].
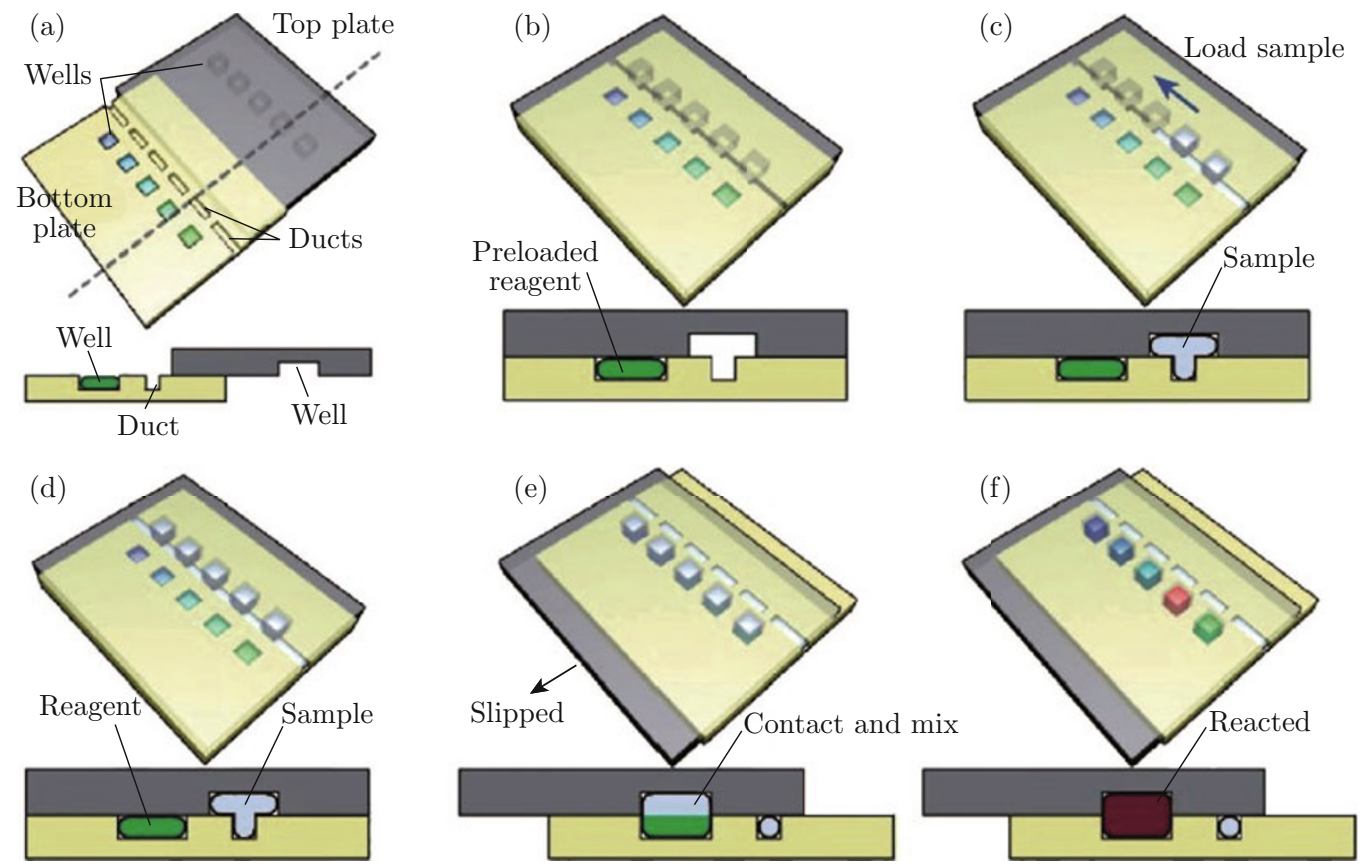

Fig. 3 The working principle of the SlipChip. (a) The preloaded wells and ducts of the bottom plate, and the wells of the top plate, (b) Creating continuous fluidic paths by moving the plates relative to one another, (c) and (d) Loading of a single sample through the fluidic path provided by the ducts and wells, (e) Slipping of the top plate relative to the bottom plate to make the sample contact, (f) A reaction taking place after mixing and incubation [42]. 
create continuous fluidic paths used for reagent delivery by moving the plates relative to one another. This approach can be utilized to generate many droplets with different reaction environment in parallel. The SlipChip requires no bonding during fabrication of chips and no valves for operation and become a valuable tool in both resource-poor and resource-rich settings in highthroughput PCR (polymerase chain reaction) [45-47], immunoassays $[48,49]$, protein crystallization [50] and screening [44].

\section{Applications in biology and medicine}

\section{Cell analysis}

Cell is the basic unit of biological morphology and life activities. So the focus has now been shifting more toward addressing the need for cell studies [16,51,52]. With the appropriate scale that matches the scales of cells, microfluidics is well positioned to contribute significantly to cell biology [52]. Rapid analysis of cells is critical in the biological, medical, and pharmaceutical communities. The first important step is to isolate and characterize single cells from a heterogeneous population. Recently, various separation techniques have been successfully applied to separate cells based on different methods, such as optical [53], dielectrophoretic [54], magnetic [55], acoustic [56] and hydrodynamic [57,58].

The team of Yu-Chong Tai in California Institute of Technology made great progress in the microminiaturization of hematology analyzer and developed a pointof-care test for the leukocyte count by using a microflow cytometer and a fluorescent dye assay as shown in Fig. 4 [59]. They demonstrated a four-part leukocyte differential count including lymphocyte, monocyte, neutrophil and eosinophil using a small amount of blood $(5 \mathrm{ml})$ and reagents $(68 \mathrm{ml}$ in total). This method is optimal for point-of-care applications due to minimal sample vol-

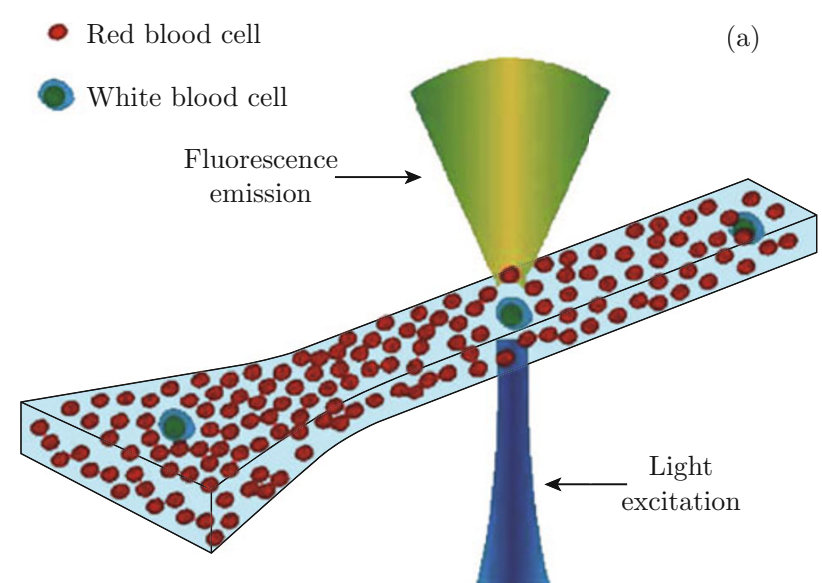

ume, long reagent shelf life and portable instrument.

It is easy to provide an accurate extracellular micro environmental in an array microfluidics due to laminar fluid flow, diffusion-based fluid mixing and closed culture volumes [2]. So it can provide an unprecedented understanding of the molecular and cellular events and thus generate successful regenerative medicine outcomes [60].

Leclerc et al. [61] developed a microfluidic chip for cell culture. The chip was composed of two stacked layers of PDMS (polydimethylsiloxane). They completed human hepatocellular carcinoma (HepG2) cell culture u successfully sing this chip.

A fully automated screening system based on a microfluidic chip that provides unattended stimulation of the cells using complex time-varying was proposed [62]. The quantitative measurements of the effect of osteogenic differentiation media and motility of primary human mesenchymal stem cells were first performed through this device. The team of Lin developed an integrated microfluidic device to characterize doxorubicin induced apoptosis in HepG2 cells [63]. It offers a unique platform to characterize various cellular responses in a high-throughput fashion by integrating the cell culture, stimulation, staining, and washing steps into a single device. In order to enhance the efficiency of pairing, a microfluidic device to trap and properly pair thousands of cells was proposed. The device contains a dense array of weir-based passive hydrodynamic cell traps. The fibroblasts, mouse embryonic stem cells and myeloma cells were tested, pairing efficiencies up to $70 \%$ were achieved, as shown in Fig. 5 [7].

Srisa-Art et al. [64] proposed droplet microfluidics as a platform technology for the identification and quantification of distinct single cells encapsulated within picoliter-sized aqueous droplets. The result was verified using conventional flow cytometry and found that both results were comparable. Bogojevic et al. [65]

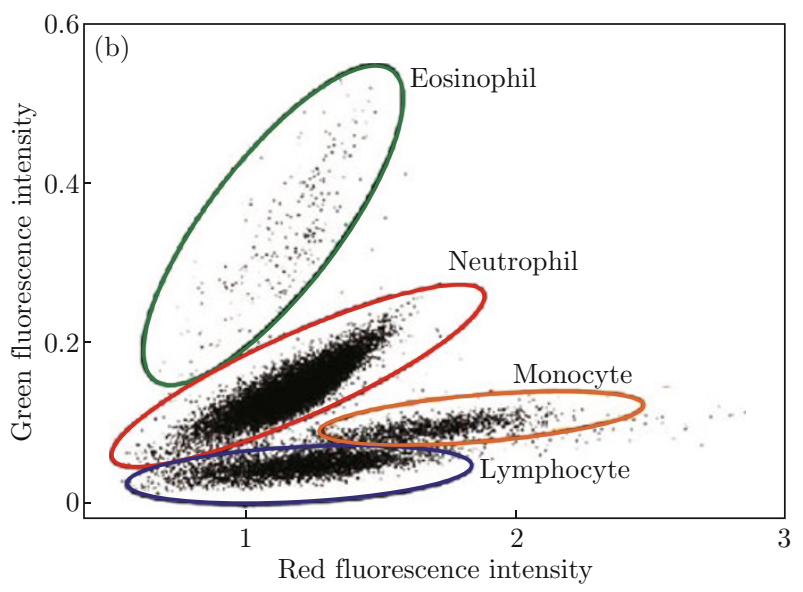

Fig. 4 (a) Basic principle of the fluorescent detection of leukocyte cells in a sheathless microfluidic channel. (b) Scatter plot of the fluorescent intensities from the leukocyte events counted in the sample [59]. 

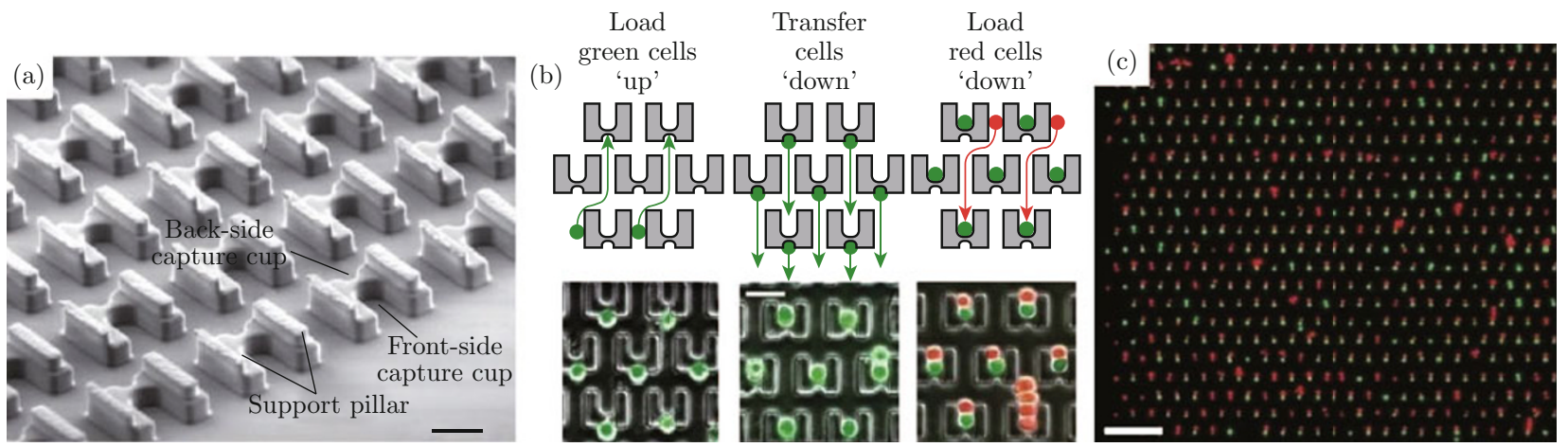

Fig. 5 (a) Detail of the pairing and fusion structure. (b) Three-step cell-loading protocol. (c) Fluorescence image of two kinds of cells [7].

presented the first droplet microfluidic platform to implement parallel-scale cell-based apoptosis assays. The platform was found to be superior to pipetting and aspiration for retaining weakly adhered apoptotic cells for analysis and a 33-fold reduction in reagent consumption relative to the conventional technique. An automated and multifunctional platform to perform flexible generation and complex manipulation of picoliter-scale droplets was developed [66]. This provides a powerful platform for achieving high efficiency research on the single cell level.

Artificial cells as simplified models of living cells which provide valuable model platforms are designed to reveal the functions of biological systems [67,68]. Microfluidics has attracted much attention as biophysical tools for investigations of the molecular basis of life [6870].

Microfluidics is also used for cancer cell detection, separation and capture [71]. It is a technical challenge to circulating tumor cells (CTCs) isolation because they are rare in the blood of patients. Microfluidics provides unique opportunities for cell sorting and rare-cell detection. The microfluidic chip, which can capture large numbers of viable CTCs in a single step from whole blood without pre-dilution, pre-labeling, pre-fixation or any other processing steps [72] had been proposed. It could further the discovery of cancer stem cell biomarkers and expand the understanding towards the biology of metastasis.

Gong et al. [73] demonstrated the drug effect analysis on cells using a high throughput droplet microfluidic chip. The result is similar to that of conventional petri dish technique, which indicates its great potential in drug effect analysis and for high throughput drug screening and discovery.

\section{Nucleic acid analysis}

Handling and characterizing samples of DNA is the key to a wide range of applications, especially molecular biology [74]. The PCR technique was first developed in 1985 [75], and has been widely used as a molecular bio- logical tool to replicate DNA by cycling through three temperature steps. After the first PCR chip to amplify DNA was introduced by Northrup et al. [76], many research groups began to study microfluidic PCR chips and developments of microfluidic PCR chips were accelerated. Currently, the microfluidic PCR chips can be classified into three distinct types: chamber stationary PCR chips [75,77], flow-through PCR chips [78,79] and thermal convection-driven PCR chips [80,81].

The working principle of this type of PCR chip is that the PCR solution is kept stationary and the temperature of the reaction chamber is cycled between three different temperatures. The stationary PCR chips can reduce the time for analysis and increase the PCR throughput because it can perform different sequential PCR tests concurrently. However, it is crucial to ensure temperature uniformity between chambers. The whole chip, including the sample, is heated and cooled through specific thermal-cycling temperatures. Therefore, chamber stationary PCR chips have high thermal inertia and long thermal-cycling time.

The working principle of this type of PCR chip is that the PCR solution is continuously flowing through three different temperature zones necessary for DNA amplification. It has advantage in rapid heat transfer and high potential for further integration. Kopp et al. [78] successfully performed the PCR in continuous flow at high speed using a micromachined chemical amplifier.

The working principle of convection PCR chip is Rayleigh-Bénard convection, which is caused by buoyancy-driven instability in a confined heated fluid layer. This convection PCR chips consist of two fixed different temperature zones. Buoyancy force is the only force to drive PCR solution flow through the temperature zones.

The PCR chip has undergone the transition from simple microfluidic components to highly integrated systems. An ideal integrated PCR chip can integrate individual microfluidic components, such as cell isolation and capture, cell lysis, DNA/RNA extraction and purification, DNA/RNA amplification, and product 


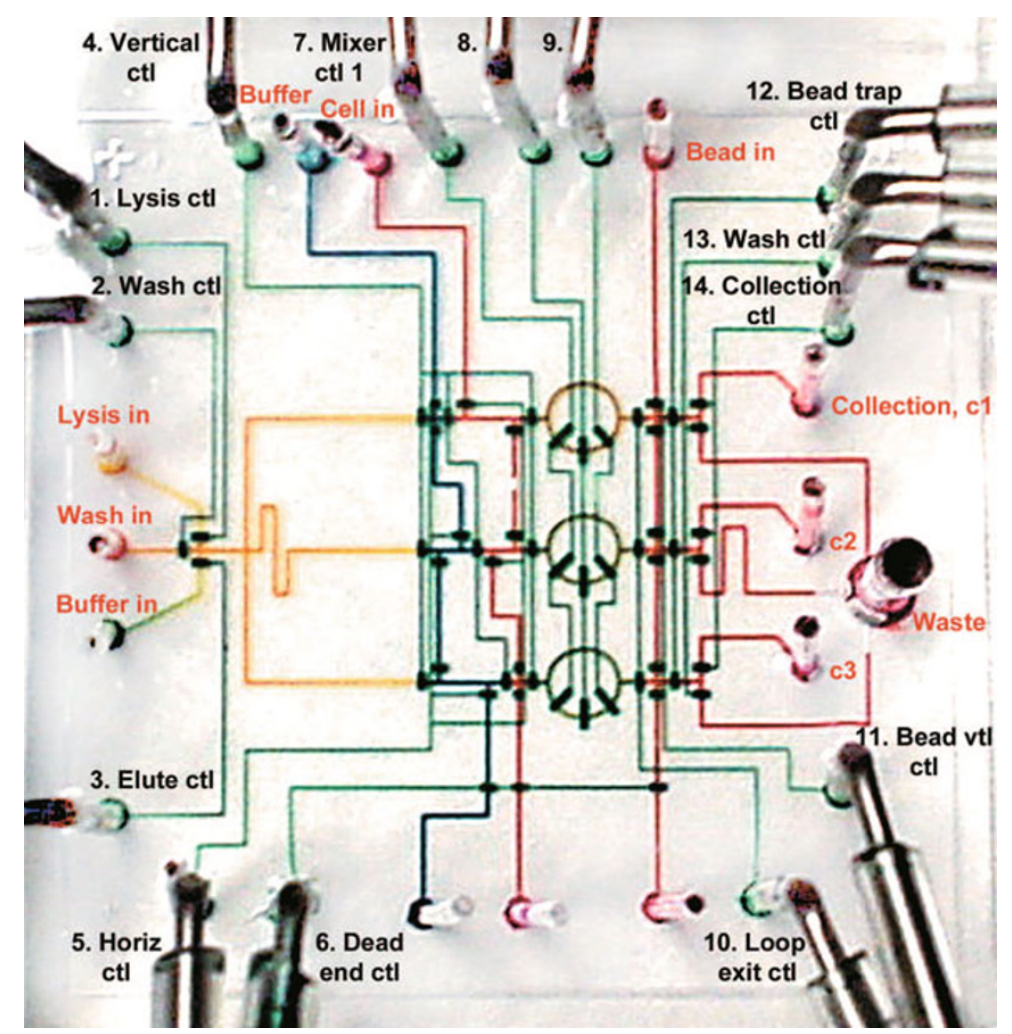

Fig. 6 Integrated PCR chip [82].

detection components into a single automated, portable chip with sample-to-answer capability. Hong et al. [82] developed microfluidic chips for automated nucleic acid purification from small numbers of bacterial or mammalian cells, as shown in Fig. 6 . The chip has 26 access holes, 1 waste hole and 54 valves within $20 \times 20 \mathrm{~mm}^{2}$, as shown in Fig. 5. The chip involves all processes in term of cell isolation, cell lysis, DNA or mRNA purification, and recovery, so any pre- or post-sample treatment is not needed. In addition, the chips are capable of processing different samples in parallel, thereby performing high-throughput characteristics.

Some researchers used surface modification methods to prevent PCR inhibition and contamination [83-85]. Schneegass et al. [83] modified the channel surface with hexamethyldisilazane (HMDS) before the injection of the PCR solution, so the hydrophobic material surface of the silicon/glass was changed to enhance surface biocompatibility. However, this method is not easy to manipulate in the sealed chip. Fortunately, the PCR inhibition and contamination can be overcome by using droplet PCR chip.

The PCR droplet microfluidics provides a solution to the limitations of throughput and cost, is able to detect single-copy target nucleic acids from a complex environment [86] associated with millions of reactions. SrisaArt et al. [87] proposed a droplet microfluidic system to solve the problems of surface contamination, rapid mixing, and rapid detection in conventional laminar mi- crofluidics. They demonstrated a high-throughput biological assay by generating droplets in a rapid and reproducible manner and monitoring them in real time. Then the temperature ramp rate has also been improved to directly increase the throughput of PCRs by allowing a faster transition between the different temperatures of each PCR cycle [88]. The bulk sample preparation 'averaging' phenomena in multi-cell PCR decrease the precision of the result. So it is necessary to create single cell high-throughput PCR. Recently, a novel high-speed droplet-PCR assay was fabricated with the ability to detect human influenza virus in less than $30 \mathrm{~min}$ [89]. Compared with screening using microtiter plate-based systems, a completely in vitro ultrahigh-throughput screening platform using dropletbased microfluidics can reduce the cost by almost 105fold, allowing the screening of 106 genes using only 150 $\mathrm{mL}$ of reagents [90]. Specially, droplet microfluidics provides the ability to perform and quantify multiple amplifications simultaneously within the same reaction volume (multiplexing) for both PCR and real-time PCR [90]. Massively parallel multiplex PCR on the singlecell level in droplets had been successfully developed. Zhu et al. [91] had developed the sensitive and quantitative analysis of a single $E$. coli $\mathrm{O} 157: \mathrm{H} 7$ cell in the high background of 100000 excess normal K12 cells and demonstrated rare pathogen detection through agarose droplet PCR microfluidic, as shown in Fig. 7(a).

Isothermal amplification methods have been 

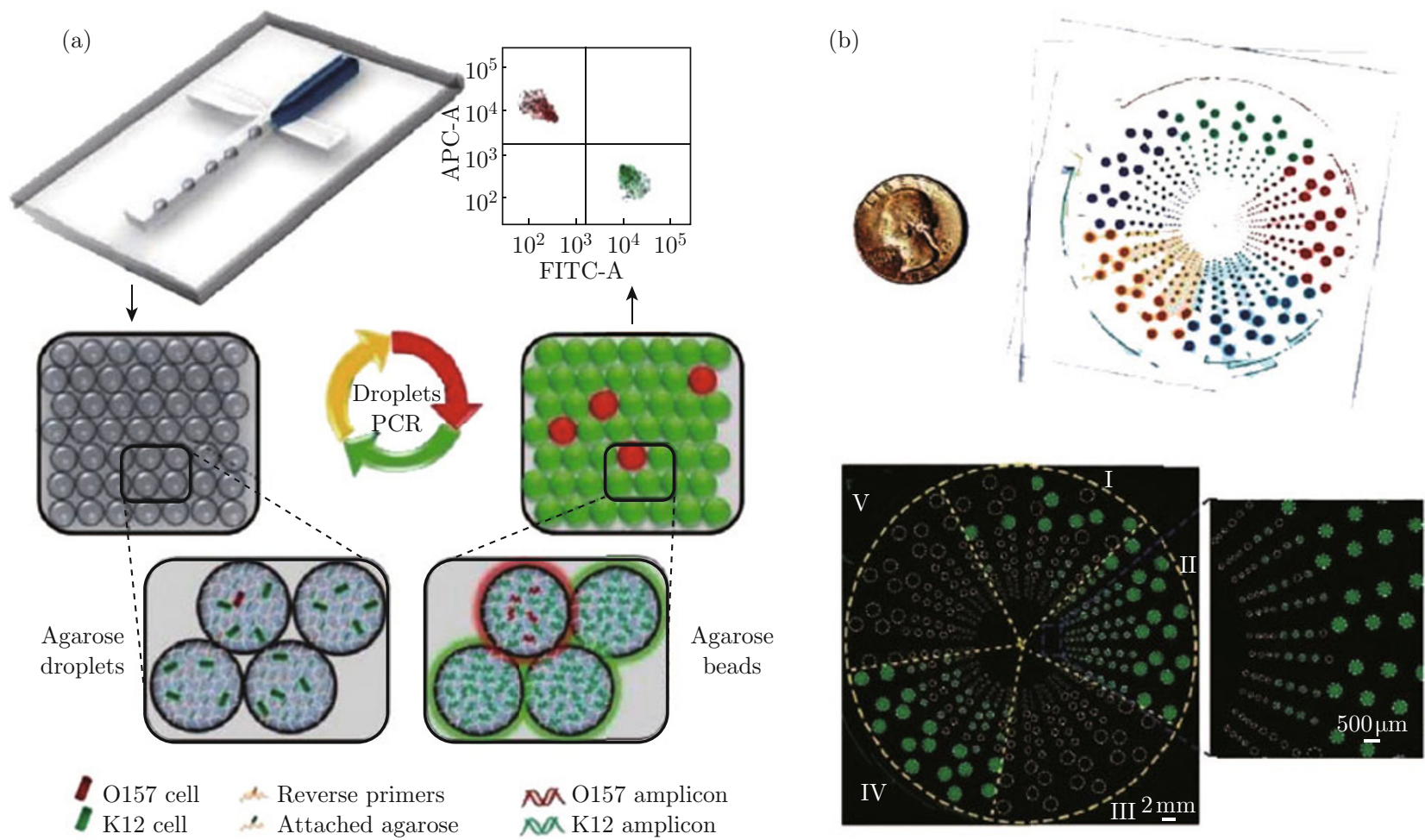

Fig. 7 (a) Schematic of rare pathogen detection by agarose droplet microfluidic single-cell PCR [91]. (b) A photograph SlipChip for multiplexed, multivolume droplet real-time PCR [47].

proposed because PCR generally requires a highly precise thermal cycler. Nucleic acid can be amplified under a single working temperature in isothermal amplification methods.

The first high-throughput, on-chip analysis droplet microfluidic system using isothermal hyperbranched rolling circle amplification (HRCA) was achieved by Mazutis et al. [92]. Then Konry et al. proposed a highly sensitive labeling method to translate antigenantibody recognition processes into DNA detection using miniaturized nanoliter reaction droplets rolling circle amplification (RCA) [93]. This method can enhance the sensitivities and specificities for various applications, including early diagnosis of cancer.

A sample self-digitization (SD) chip with automated, loss-less digitization of sample volumes on-chip was described. They demonstrated accurate quantification of relative and absolute DNA concentrations using digital loop-mediated DNA amplification (dLAMP) [94]. It is an inexpensive and easy-to-operate device for DNA amplification.

This SlipChip can also be applied to perform highthroughput PCRs. Ismagilov et al. [45] first proposed a very simple and inexpensive SlipChip to perform droplet PCR. Then they described high-throughput nanoliter multiplex PCR using SlipChip platform with robust performance and lack of false negatives, false positives, and cross-contamination [46]. They used up to 384 nanoliter-scale reactions for multiplex PCR with a preloaded array of primer pairs. Recently, they designed a microfluidic rotational multivolume droplet real-time PCR SlipChip to performance viral HIV and HCV RNA for high-performance diagnostics, as shown in Fig. 7(b) [47].

Mathies developed high throughput DNA sequencing by using a microfabricated 96-channel radial capillary array electrophoresis microchannel plate [95]. The system can produce sequencing data at a rate of 1.7 $\mathrm{kbp} / \mathrm{min}$, a 5 -fold increase at lower reagent volumes and lower sample concentrations. It presents great potential for high performance DNA sequencing platform with integrated sample preparation and handling.

DNA computer is based on the computational model of DNA biochemical reaction [96]. And they experimentally demonstrated that DNA molecules could be used to solve hard combinatorial problems. Then hairpin formation by single-stranded DNA molecules was exploited to explore the feasibility of autonomous molecular computing, which sheds a new light on the potentials of DNA [97]. Gehani and Rief [98] first proposed a bio-molecular computation model with the recombinant DNA technology and micro-flow technology. The DNA computer model must integrate MEMS pumps, valves, sensors, actuators, flow control systems and digital to analog conversion. Grover and Mathies [99] developed an integrated microfluidic processor to performs molecular computations using single nucleotide polymorphisms (SNPs) as binary bits, as shown in Fig. 8. 

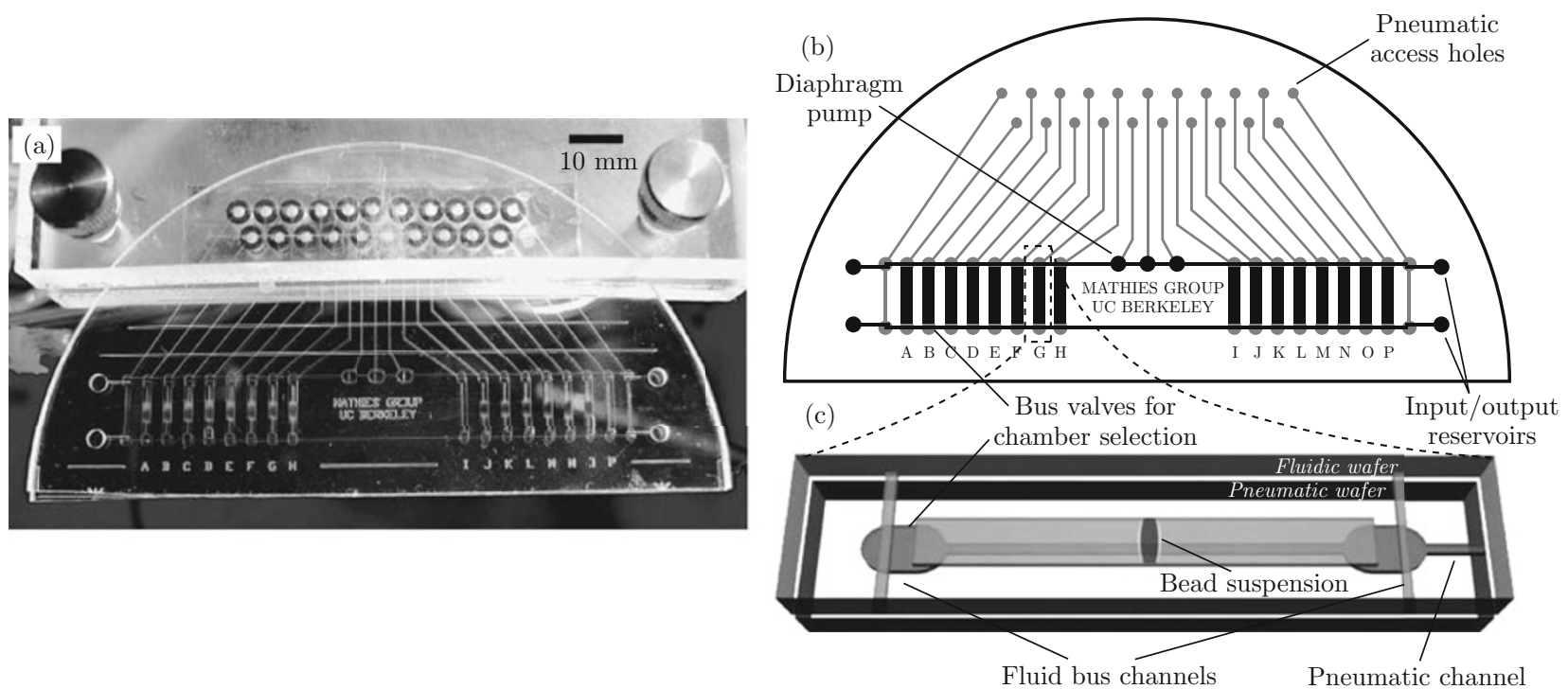

Fig. 8 (a) Photograph and (b) mask design of the microfluidic processor. (c) Oblique view of a single capture chamber [99].
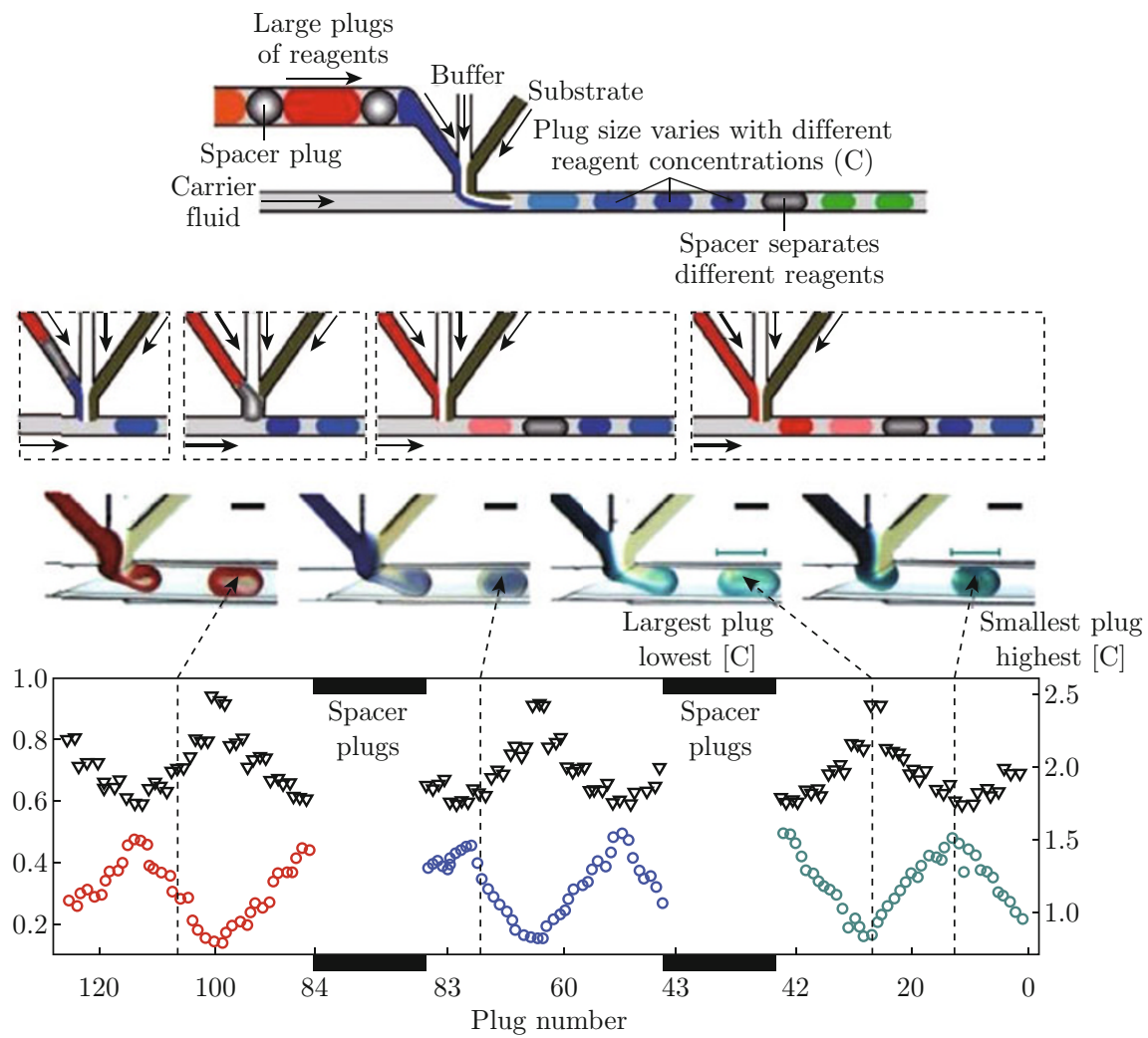

$\nabla$ Rel. plug length $\circ$ Rel. concentration

Fig. 9 Schematic illustration of the "hybrid" droplet microfluidics for protein crystallization and a plot quantifying a hybrid screen, performed in a separate experiment [103].

It suited for performing larger-scale DNA computations well and offered a valuable platform for many types of next-generation molecular computations.

\section{Protein engineering}

Protein engineering is becoming increasingly important in industrial biotechnology-based manufacturing of commodities related to bioenergy and biosustainabilitys [100]. A rapid screening method has been developed to determine binding affinities for proteinprotein interactions in a microfluidic platform [101]. The method reduced the experimental duration by more than 10-fold comparing with the conventional ki- 
netic exclusion assay method.

In droplet microfluidics, many droplets, each containing different crystallization conditions, can be generated in a single experiment by systematically changing the flow rates of the streams of aqueous reagent, protein, buffer, and precipitants. Zheng et al. [102] proposed a microfluidic system for screening hundreds of protein crystallization conditions using less than $4 \mathrm{~nL}$ of protein solution for each crystallization trial. This chip has the ability to handle 5-10 solutions and provides multidimensional phase diagrams for protein crystallization. So this system offers the potential to serve as the basis of high-throughput, automated crystallization systems. High-throughput screening and optimization experiments are critical to biology. Then Li et al. [103] reported a "hybrid" droplet microfluidics approach to combines high-throughput screening and optimization into one simple experiment, as shown in Fig. 9. In addition, this approach uses nanoliter-sized plugs to minimize sample consumption. Recently, droplet microfluidics is also used to perform high-throughput analysis of protein-protein interactions [104]. Compared with equivalent bulk assays, this method only using $14 \mathrm{~nL}$ of sample in per experiment represents a reduction of 4 orders of magnitude.

Ismagilov et al. [50] provided a convenient and highthroughput SlipChip-based approach for protein crystallization. The composite SlipChip was designed to screen multiple reagents, each at multiple mixing ratios and multiple equilibration times.

\section{High-throughput screening}

High-throughput screening can provide an enormous amount of information and is considered as a new technology for the 21st century [105]. Recently, microfluidic-based high-throughput screening is becoming an attractive alternative to conventional laboratorybased screening. However, it is challenging to control and vary the concentration of the analytical sample under investigation [106]. Niu et al. [106] developed a dilution module for high-throughput screening using droplet microfluidics. They generated a sequence of output droplets with droplet concentration gradient through a process of droplet merging, mixing and resplitting. It is an inexpensive chip-level screening technology for high-throughput and high-efficiency experimentation.

Granieri et al. [107] reported a microfluidic approach for the high-throughput screening of structurally complex enzyme variants. The droplet microfluidic system allows a throughput over 100 times higher and reduces cost almost one million-fold lower than conventional screening formats such as microtiter plates. Brouzes et al. [108] developed a fully integrated droplet microfluidic workflow that enables high-throughput screening of single mammalian cells, as shown in Fig. 10. It is a generic, fast, and robust tool that can be used largescale screen and analysis of small samples. Recently, a modular approach to droplet-based screening was proposed, which included droplets library generation, storage, mixing, and optical detection [109].

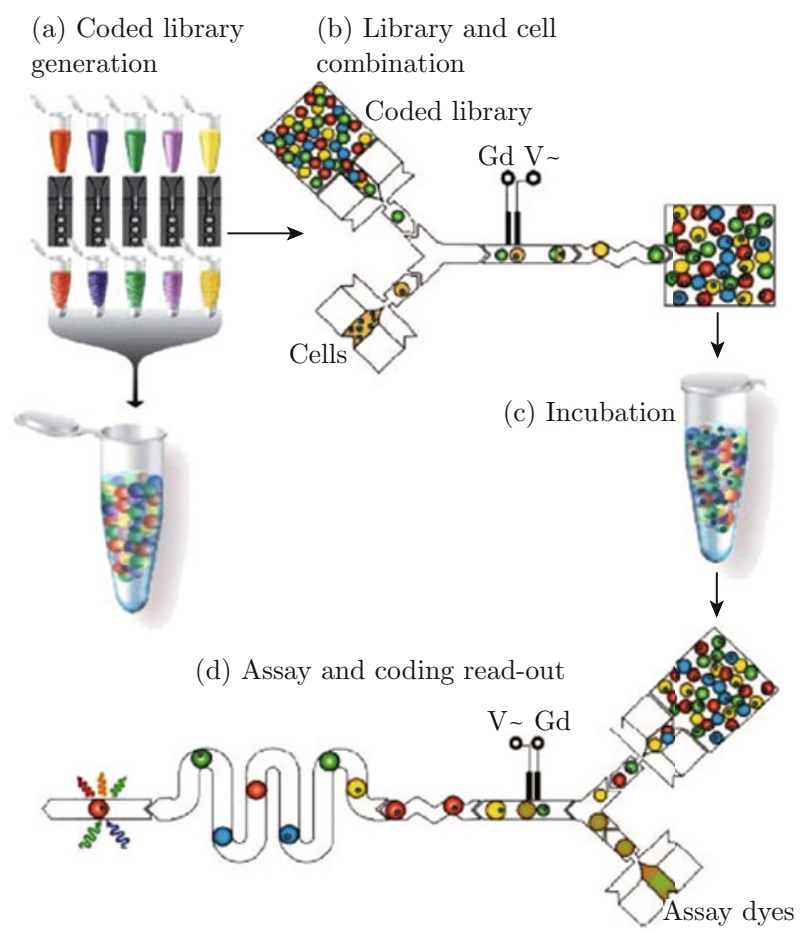

Fig. 10 Droplet microfluidic workflow for single-cell highthroughput screening [108].

\section{Conclusions}

In summary, we provided a comprehensive review of the technologies for microfluidics and its applications in biology and medicine. Microfluidics has been considered as a potential technology to miniaturize the conventional equipments and technologies. It offers advantages such as small volume, low cost, short reaction time and high-throughput. We provide the physics of microfluidics to understand the physical phenomena at the microscale. Then we introduce a summary of droplet microfluidics technology with droplet generation and manipulation and an ingenious SlipChip. Finally, we discuss these recent advances of microfluidics in biology and medicine, such as cell analysis, nucleic acid analysis, protein engineering and high-throughput screening. Cell culture, fusion and apoptosis were successfully performed in microfluidics due to the appropriate scale matching the scales of cells. Microfluidics provides unique opportunities for rare circulating tumor cells isolation and detection from the blood of patients, which furthers the discovery of cancer stem cell biomarkers and expands the understanding of the biol- 
ogy of metastasis. Nucleic acid analysis in microfluidics has been extended to single-molecule, high-throughput and integration treatment in one chip. DNA computer which is based on the computational model of DNA biochemical reaction will become practice from concept in the future. In addition, microfluidics offers a versatile platform for protein-protein interactions, protein crystallization and high-throughput screening. Although microfluidics is still in its infancy, its great potential has already been demonstrated and will provide novel solutions to the high-throughput applications. Even though microfluidics is still in the early stages, we believe that the potentials of microfluidics for high-throughput applications have yet to be fully investigated and exploited. Moreover, we anticipate that microfluidics will be increasingly used in science and technology.

\section{Acknowledgements}

The authors sincerely thank Ministry of Science and Technology of China (No. 2010CB933901) and Science and Technology Innovation fund of SJTU-University of Michigan

\section{References}

[1] G. M. Whitesides, "The origins and the future of microfluidics", Nature 442, 368-373 (2006). http://dx. doi.org/10.1038/nature05058

[2] A. Manz, N. Graber and H.M. Widmer, "Miniaturized total chemical analysis systems: a novel concept for chemical sensing", Sens. Actuators B 1, 244-248 (1990). http://dx.doi.org/10.1016/ 0925-4005 (90) 80209-I

[3] D. Lombardi and P. S. Dittrich, "Advances in microfluidics for drug discovery", Expert Opin. Drug Dis. 5, 1081-1094 (2010). http://dx.doi.org/10.1517/ 17460441.2010 .521149

[4] T. Thorsen, S. J. Maerkl and S. R. Quake, "Microfluidic large-scale integration", Science 298, 580584 (2002). http://dx.doi.org/10.1126/science. 1076996

[5] A. J. Demello, "Control and detection of chemical reactions in microfluidic systems", Nature 442, 394-402 (2006). http://dx.doi.org/10.1038/nature05062

[6] X. D. Fan and I. M. White, "Optofluidic microsystems for chemical and biological analysis", Nature Photon. 5, 591-597 (2011). http://dx.doi.org/10.1038/ nphoton. 2011.206

[7] A. M. Skelley, O. Kirak, H. Suh, R. Jaenisch, and J. Voldman, "Microfluidic control of cell pairing and fusion", Nat. Methods 6, 147-152 (2009). http://dx. doi.org/10.1038/nmeth. 1290

[8] J. D. Chen, D. Chen, T. Yuan and X. Chen, "Microfluidic PCR chips", Nano Biomed. Eng. 3, 203210 (2011). http://dx.doi.org/10.5101/nbe.v3i4. p203-210
[9] P. S. Dittrich and A. Manz, "Lab-on-a-chip: microfluidics in drug discovery", Nat. Rev. Drug Discov. 5, 210218 (2006). http://dx.doi.org/10.1038/nrd1985

[10] H. X. Du, Z. G. Wang, Z. L. Yang, D. Chen, J. D. Chen and R. J. Hu, "Separation of circulating cancer cells by unique microfluidic chip in colorectal cancer" Oncology Research 19, 487-500 (2012). http://dx.doi.org/10. $3727 / 096504012 \times 13286534482476$

[11] Y. J. Song, J. Hormes and C. S. S. R. Kumar, "Microfluidic synthesis of nanomaterials", Small 4, 698-711 (2008). http://dx.doi.org/10.1002/smll. 200701029

[12] I. Doh, E. Y. Erdem and A. P. Pisano, "Trapping and collection of uniform size droplets for nanoparticle synthesis", Appl. Phys. Lett. 100, 074106-074108 (2012) http://dx.doi.org/10.1063/1.3685695

[13] N. Yamaguchi, M. Torii, Y. Uebayashi and M. Nasu, "Rapid, semiautomated quantification of bacterial cells in freshwater by using a microfluidic device for on-chip staining and counting", Appl. Environ. Microbiol. 77, 1536-1539 (2011). http://dx.doi .org/10. 1128/aem.01765-10

[14] S. Neethirajan, I. Kobayashi, M. Nakajima, D. Wu, S. Nandagopal and F. Lin, "Microfluidics for food, agriculture and biosystems industries", Lab Chip 11, 1574-1586 (2011). http://dx.doi.org/10.1039/ c01c00230e

[15] H. A. Stone, A. D. Stroock and A. Ajdari, "Engineering flows in small devices microfluidics toward a lab-on-a-chip", Annu. Rev. Fluid Mech., 36, 381411 (2004). http://dx.doi.org/10.1146/annurev . fluid.36.050802.122124

[16] D. J. Beebe, G. A. Mensing and G. M. Walker, "Physics and applications of microfluidics in biology", Annu. Rev. Biomed. Eng. 4, 261-286 (2002). http:// $\mathrm{dx}$.doi .org/10.1146/annurev . bioeng . 4.112601. 125916

[17] G. F. Christopher and S. L. Anna, "Microfluidic methods for generating continuous droplet streams", J. Phys. D: Appl. Phys. 40, R319-R336 (2007). http:// dx.doi.org/10.1088/0022-3727/40/19/R01

[18] V. Hessel, H. Löwe and F. Schönfeld, "Micromixers-a review on passive and active mixing principles", Chem. Eng. Sci. 60, 2479-2501 (2005). http://dx.doi.org/ $10.1016 / j$.ces. 2004.11.033

[19] L. Capretto, W. Cheng, M. Hill and X. Zhang, "Micromixing within microfluidic devices", Top. Curr. Chem. 304, 27-68 (2011). http://dx.doi.org/10. 1007/128_2011_150

[20] P. B. Umbanhowar, V. Prasad and D. A. Weitz, "Monodisperse emulsion generation via drop break off in a coflowing stream", Langmuir 16, 347-351 (2000). http://dx.doi.org/10.1021/la990101e

[21] T. Thorsen, R. W. Roberts, F. H. Arnold and S. R. Quake, "Dynamic pattern formation in a vesiclegenerating microfluidic device", Phys. Rev. Lett. 86, 4163-4166 (2001). http://dx.doi.org/10.1103/ physrevlett. 86.4163 
[22] S. L. Anna, N. Bontoux and H. A. Stone, "Formation of dispersions using "flow focusing" in microchannels", Appl. Phys. Lett. 82, 364-366 (2003). http://dx.doi . org/10.1063/1.1537519

[23] C. N. Baroud, F. Gallaire and R. Dangla, "Dynamics of microfluidic droplets", Lab Chip 10, 2032-2045 (2010). http://dx.doi.org/10.1039/c001191f

[24] S. Y. Teh, R. Lin, L. H. Hung and A. P. Lee, "Droplet microfluidics" Lab Chip 8, 198-220 (2008). http://dx . doi.org/10.1039/b715524g

[25] A. S. Utada, A. Fernandez-Nieves, H. A. Stone and D. A. Weitz, "Dripping to jetting transitions in coflowing liquid streams", Phys. Rev. Lett. 99, 94502-94505 (2007). http://dx.doi.org/10.1103/ PhysRevLett.99.094502

[26] X. C. I. Solvas and A. deMello, "Droplet microfluidics: recent developments and future application", Chem. Commun. 47, 1936-1942 (2011). http://dx.doi.org/ 10.1039/c0cc02474k

[27] A. C. Hatch, J. S. Fisher, A. R. Tovar, A. T. Hsieh, R. Lin, S. L. Pentoney, D. L. Yang and A. P. Lee, "1million droplet array with wide-field fluorescence imaging for digital PCR", Lab Chip 11, 3838-3845 (2011). http://dx.doi.org/10.1039/c1lc20561g

[28] N. Bremond, A. R. Thiam and J. Bibette, "Decompressing emulsion droplets favors coalescence", Phys. Rev. Lett. 100, 24501-24504 (2008). http://dx.doi. org/10.1103/PhysRevLett. 100.024501

[29] L. Mazutis, J. C. Baret and A. D. Griffiths, "A fast and efficient microfluidic system for highly selective oneto-one droplet fusion", Lab Chip 9, 2665-2672 (2009). http://dx.doi.org/10.1039/b903608c

[30] M. Chabert, K. D. Dorfman and J. L. Viovy, "Droplet fusion by alternating current (AC) field electrocoalescence in microchannels", Electrophoresis 26, 3706-3715 (2005). http://dx.doi.org/0.1002/elps. 200500109

[31] R. M. Lorenz, J. S. Edgar, G. D. M. Jeffries and D.T. Chiu, "Microfluidic and optical systems for the on-demand generation and manipulation of single femtoliter-volume aqueous droplets", Anal. Chem. 78, 6433-6439 (2006). http://dx.doi.org/10.1021/ ac0607481

[32] D. Link, S. L. Anna, D. A. Weitz and H. Stone, "Geometrically mediated breakup of drops in microfluidic devices", Phys. Rev. Lett. 92, 54503-54506 (2004). http://dx.doi.org/10.1103/ PhysRevLett.92.054503

[33] A. M. Leshansky and L. M. Pismen, "Breakup of drops in a microfluidic T junction", Phys. Fluids 21, 023303 (2009). http://dx.doi.org/10.1063/1.3078515

[34] J. H. Choi, S. K. Lee, J. M. Lim, S. M. Yang and G. R. $\mathrm{Yi}$, "Designed pneumatic valve actuators for controlled droplet breakup and generation", Lab Chip 10, 456461 (2010). http://dx.doi.org/10.1039/b915596a

[35] A. R. Abate and D. A. Weitz, "Faster multiple emulsification with drop splitting", Lab Chip 11, 1911-1915 (2011). http://dx.doi.org/10.1039/c01c00706d

[36] H. Song, M. R. Bringer, J. D. Tice, C. J. Gerdts and R. F. Ismagilov, "Experimental test of scaling of mix- ing by chaotic advection in droplets moving through microfluidic channels", Appl. Phys. Lett. 83, 46644666(2003). http://dx.doi.org/10.1063/1.1630378

[37] M. R. Bringer, C. J. Gerdts, H. Song, J. D. Tice and R. F. Ismagilov, "Microfluidic systems for chemical kinetics that rely on chaotic mixing in droplets", Phil. Trans. R. Soc. Lond. A 362, 1087-1104 (2004). http: // dx.doi.org/10.1098/rsta.2003.1364

[38] N. T. Nguyen and Z. Wu, Microm, "Micromixers-a review", J. Micromech. Microeng. 15, R1-R16 (2005). http://dx.doi.org/10.1088/0960-1317/15/2/R01

[39] A. Huebner, D. Bratton, G. Whyte, M. Yang, C. Abell and F. Hollfelder, "Static microdroplet arrays: a microfluidic device for droplet trapping, incubation and release for enzymatic and cell-based assays", Lab Chip 9, 692-698 (2009). http://dx.doi.org/10.1039/ b813709a

[40] Y. P. Bai, X. M. He, D. S. Liu, S. N. Patil, D. Bratton, A. Huebner, F. Hollfelder, C. Abell and W. T. S. Huck, "A double droplet trap system for studying mass transport across a droplet-droplet interface", Lab Chip 10, 1281-1285 (2010). http://dx.doi.org/ 10. $1039 / \mathrm{b} 925133 \mathrm{~b}$

[41] J. Xu, B. Ahn, H. Lee, L. F. Xu, K. Lee, R. Panchapakesan and K. W. Oh, "Droplet-based microfluidic device for multiple-droplet clustering", Lab Chip 12, 725-730 (2012). http://dx.doi.org/10. 1039/c2lc20883k

[42] W. B. Du, L. Li, K. P. Nichols and R. F. Ismagilov, "SlipChip", Lab Chip 9, 2286-2292 (2009). http://dx. doi.org/10.1039/b908978k

[43] L. Li, W. B. Du and R. F. Ismagilov, "User-loaded SlipChip for equipment-free multiplexed nanoliterscale experiments", J. Am. Chem. Soc. 132, 106-111 (2009). http://dx.doi.org/10.1021/ja908555n

[44] D. Belder, "Screening in one sweep using the SlipChip", Angew. Chem. Int. Ed. 49, 64846486 (2010). http://dx.doi.org/10.1002/anie. 201002059

[45] F. Shen, W. B. Du, J. E. Kreutz, A. Fok and R. F. Ismagilov, "Digital PCR on a SlipChip", Lab Chip 10, 2666-2672 (2010). http://dx.doi.org/10.1039/ c004521g

[46] F. Shen, W. B. Du, E. K. Davydova, M. A. Karymov, J. Pandey and R. F. Ismagilov, "Nanoliter multiplex PCR arrays on a SlipChip", Anal. Chem. 82, 4606-4612 (2010). http://dx.doi.org/10.1021/ac1007249

[47] F. Shen, B. Sun, J. E. Kreutz, E. K. Davydova, W. B. Du, P. L. Reddy, L. J. Joseph, and R. F. Ismagilov, "Multiplexed quantification of nucleic acids with large dynamic range using multivolume digital RT-PCR on a rotational SlipChip tested with HIV and Hepatitis C viral load", J. Am. Chem. Soc. 133, 17705-177712 (2011). http://dx.doi.org/10.1021/ja2060116

[48] W. S. Liu, D. L. Chen, W. B. Du, K. P. Nichols and R. F. Ismagilov, "SlipChip for immunoassays in nanoliter volumes", Anal. Chem. 82, 3272-3282 (2010). http:// dx.doi.org/10.1021/ac100044c 
[49] C. Martino, M. Zagnoni, M. E. Sandison, M. Chanasakulniyom, A. R. Pitt and J. M. Cooper, "Intracellular protein determination using droplet-based immunoassays", Anal. Chem. 83, 5361-5368 (2011). http://dx.doi.org/10.1021/ac200876q

[50] L. Li, W. Du and R. F. Ismagilov, "Multiparameter screening on SlipChip used for nanoliter protein crystallization combining free interface diffusion and microbatch methods", J. Am. Chem. Soc. 132, 112-119 (2009). http://dx.doi.org/10.1021/ja908558m

[51] P. Mitchell, "Microfluidics - downsizing large-scale biology", Nature Biotechnology 19, 717-721 (2001). http://dx.doi.org/10.1038/90754

[52] A. A. S. Bhagat, H. Bow, H. W. Hou, S. J. Tan, J. Han and C. T. Lim, "Microfluidics for cell separation", Med. Biol. Eng. Comput. 48, 999-1014 (2010). http: // dx.doi.org/10.1007/s11517-010-0611-4

[53] M. Murata, Y. Okamoto, Y. S. Park, N. Kaji, M. Tokeshi and Y. Baba, "Cell separation by the combination of microfluidics and optical trapping force on a microchip", Anal. Bioanal. Chem. 394, 277-283 (2009). http://dx.doi.org/10.1007/s00216-009-2648-5

[54] W. Y. Lin, Y. H. Lin and G. B. Lee, "Separation of micro-particles utilizing spatial difference of optically induced dielectrophoretic forces", Microfluid. Nanofluid. 8, 217-229 (2010). http://dx.doi.org/10. 1007/s10404-009-0457-y

[55] M. S. Sakar, E. B. Steager, M. J. Kim, G. J. Pappas and V. Kumar, "Single cell manipulation using ferromagnetic composite microtransporters", Appl. Phys. Lett. 96, 043705-043707 (2010). http://dx.doi.org/ 10.1063/1.3293457

[56] T. Laurell, F. Petersson and A. Nilsson, "Chip integrated strategies for acoustic separation and manipulation of cells and particles", Chem. Soc. Rev. 36, 492506 (2006). http://dx.doi.org/10.1039/b601326k

[57] D. Di Carlo, L. Y. Wu and L. P. Lee, "Dynamic single cell culture array", Lab Chip, 6, 1445-1449 (2006). http://dx.doi.org/10.1039/b605937f

[58] H. W. Wu, C. C. Lin and G. B. Lee, "Stem cells in microfluidics", Biomicrofluidics 5, 013401-013426 (2011). http://dx.doi.org/10.1063/1.3528299

[59] W. Shi, L. Guo, H. Kasdan and Y.C. Tai, "Fourpart leukocyte differential count based on sheathless microflow cytometer and fluorescent dye assay", Lab Chip 13, 1257-1265 (2013). http://dx.doi.org/10. 1039/c3lc41059e

[60] D. M. Titmarsh, H. Chen, E. J. Wolvetang and J. J. Cooper-White, "Arrayed cellular environments for stem cells and regenerative medicine", Biotechnol. J 8, 167-179 (2012). http://dx.doi.org/10.1002/ biot. 201200149

[61] E. Leclerc, Y. Sakai and T. Fujii, "Biomed. Cell Culture in 3-Dimensional Microfluidic Structure of PDMS (polydimethylsiloxane) ", Microdevices 5, 109-114 (2003). http://dx.doi.org/10.1023/A: 1024583026925

[62] R. Gomez-Sjoberg, A. A. Leyrat, D. M. Pirone, C. S. Chen and S. R. Quake, Versatile, "Fully auto- mated, microfluidic cell culture system", Anal. Chem. 79, 8557-8563 (2007). http://dx.doi.org/10.1021/ ac071311w

[63] N. Ye, J. H. Qin, X. Liu, W. W. Shi and B. C. Lin, "Characterizing doxorubicin-induced apoptosis in HepG2 cells using an integrated microfluidic device", Electrophoresis 28, 1146-1153 (2007). http://dx.doi. org/10.1002/elps. 200600450

[64] M. Srisa-Art, I. C. Bonzani, A. Williams, M. M. Stevens and J. B. Edel, "Identification of rare progenitor cells from human periosteal tissue using droplet microfluidics", Analyst 134, 2239-2245 (2009). http:// dx.doi.org/10.1039/b910472k

[65] D. Bogojevic, M. D. Chamberlain, I. BarbulovicNad and A. R. Wheeler, "A digital microfluidic method for multiplexed cell-based apoptosis assays", Lab Chip 12, 627-634 (2012). http://dx.doi.org/10. 1039/c2lc20893h

[66] S. Q. Gu, Y. X. Zhang, Y. Zhu, W. B. Du, B. Yao and Q. Fang, "Multifunctional picoliter droplet manipulation platform and its application in single cell analysis", Anal. Chem. 83, 7570-7576 (2011). http:// dx.doi.org/10.1021/ac201678g

[67] P. Stano and P. L. Luisi, "Achievements and open questions in the self-reproduction of vesicles and synthetic minimal cells", Chem. Commun. 46, 3639-3653 (2010). http://dx.doi.org/10.1039/b913997d

[68] M. Takinoue and S. Takeuchi, "Droplet microfluidics for the study of artificial cells", Anal. Bioanal. Chem. 400, 1705-1716 (2011). http://dx.doi.org/10.1007/ s00216-011-4984-5

[69] A. Jimenez, M. Roché, M. Pinot, P. Panizza, L. Courbin and Z. Gueroui, "Towards high throughput production of artificial egg oocytes using microfluidics", Lab Chip 11, 429-434 (2010). http://dx.doi. org/10.1039/c01c00046a

[70] S. Matosevic and B. M. Paegel, "Stepwise synthesis of giant unilamellar vesicles on a microfluidic assembly line", J. Am. Chem. Soc. 133, 2798-2800 (2011). http://dx.doi.org/10.1021/ja109137s

[71] J. Chen, J. Li and Y. Sun, "Microfluidic approaches for cancer cell detection, characterization, and separation", Lab Chip 12, 1753-1767 (2012). http://dx. doi.org/10.1039/c2lc21273k

[72] S. Nagrath, L. V. Sequist, S. Maheswaran, et al. "Isolation of rare circulating tumour cells in cancer patients by microchip technology", Nature 450, 1235-1239 (2007). http://dx.doi.org/10.1038/nature06385

[73] Z. C. Gong, H. Zhao, T. H. Zhang, et al. "Drug effects analysis on cells using a high throughput microfluidic chip", Biomed. Microdevices 13, 215-219 (2011). http://dx.doi.org/10.1007/s10544-010-9486-2

[74] M. J. Jebrail, M. S. Bartsch and K. D. Patel, "Digital microfluidics: a versatile tool for applications in chemistry, biology and medicine", Lab Chip 12, 2452-2463 (2012). http://dx.doi.org/10.1039/c2lc40318h

[75] R. K. Saiki, S. Scharf, F. Faloona, K. B. Mullis, G. T. Horn, H. A. Erlich and N. Arnheim, "Enzymatic amplification of beta-globin genomic sequences and re- 
striction site analysis for diagnosis of sickle cell anemia", Science 230, 1350-1354 (1985). http://dx.doi. org/10.1126/science. 2999980

[76] M. A. Northrup, M. T. Ching, R. M. White and R. T. Watson. In tranducer'93, seventh international conference on solid state Sens Actuators, Yokohama, Japan. ISBN: 4-9900247-2-9. 924 (1993).

[77] H. Nagai, Y. Murakami, Y. Morita, K. Yokoyama and E. Tamiya, "Development of a microchamber array for picoliter PCR", Anal. Chem. 73, 1043-1047 (2001). http://dx.doi.org/10.1021/ac000648u

[78] M. U. Kopp, A. J. De Mello and A. Manz, "Chemical amplification: continuous-flow PCR on a chip", Science 280, 1046-1048 (1998). http://dx.doi.org/10. 1126/science. 280.5366.1046

[79] W. M. Wu and N.Y. Lee, "Three-dimensional onchip continuous-flow polymerase chain reaction employing a single heater", Anal. Bioanal. Chem. 400, 2053-2060 (2011). http://dx.doi.org/10.1007/ s00216-011-4947-x

[80] K. H. Chung, Y. H. Choi and M. Y. Jung, "Natural convection PCR in a disposable polymer chip", IEEE SENSORS 1-3, 1217-1220 (2009). http://dx. doi.org/10.1109/ICSENS . 2009.5398367

[81] D. Braun, "PCR by thermal convection", Mod. Phys. Lett. B 18, 775-784 (2004). http://dx.doi.org/10. 1142/S0217984904007049

[82] J. W. Hong, V. Studer, G. Hang, W. F. Anderson and S.R. Quake, "A nanoliter-scale nucleic acid processor with parallel architecture", Nat. Biotechnol. 22, 435439 (2004). http://dx.doi.org/10.1038/nbt951

[83] I. Schneegass, R. Brautigam and J.M. Kohler, "Miniaturized flow-through PCR with different template types in a silicon chip thermocycler", Lab Chip 1, 4249 (2001). http://dx.doi.org/10.1039/b103846j

[84] T. Fukuba, T. Yamamoto, T. Naganuma and T. Fujii, "Microfabricated flow-through device for DNA amplification-towards in situ gene analysis", Chem. Eng. J. 101, 151-156 (2004). http://dx.doi.org/10. $1016 / j \cdot c e j \cdot 2003.11 .016$

[85] J. A. Kim, J. Y. Lee, S. Seong, S. H. Cha, S. H. Lee, J. J. Kim and T.H. Park, "Fabrication and characterization of a PDMS-glass hybrid continuous-flow PCR chip", Biochem. Eng. J. 29, 91-97 (2006). http://dx. doi.org/10.1016/j.bej.2005.02.032

[86] M. M. Kiss, L. Ortoleva-Donnelly, N. R. Beer, et al., "High-throughput quantitative polymerase chain reaction in picoliter droplets", Anal. Chem. 80, 8975-8981 (2008). http://dx.doi.org/10.1021/ac801276c

[87] M. Srisa-Art, A. J. deMello and J. B. Edel, "Highthroughput DNA droplet assays using picoliter reactor volumes", Anal. Chem. 79, 6682-6689 (2007). http:// dx.doi.org/10.1021/ac070987o

[88] A. L. Markey, S. Mohr and P. J. R. Day, "Highthroughput droplet PCR", Methods 50, 277-281 (2010). http://dx.doi.org/10.1016/j.ymeth. 2010 . 01.030

[89] K. Matsuda, A. Yamaguchi, C. Taira, A. Sueki, H. Koeda, F. Takagi, M. Sugano and T. Honda, "A novel high-speed droplet-polymerase chain reaction can detect human influenza virus in less than 30 min", Clinica Chimica Acta 413, 1742-1745 (2012). http://dx.doi. org/10.1016/j.cca.2012.06.026

[90] A. Fallah-Araghi, J. C. Baret, M. Ryckelynck and A. D. Griffiths, "A completely in vitro ultrahighthroughput droplet-based microfluidic screening system for protein engineering and directed evolution", Lab Chip 12, 882-891 (2012). http://dx.doi.org/10. $1039 /$ c2lc21035e

[91] Z. Zhu, W. H. Zhang, X. F. Leng, M. X. Zhang, Z. C. Guan, J. Q. Liu and C. J. Yang, "Highly sensitive and quantitative detection of rare pathogens through agarose droplet microfluidic emulsion PCR at the single-cell level", Lab Chip 12, 3907-3913 (2012). http://dx.doi.org/10.1039/c2lc40461c

[92] L. Mazutis, A. F. Araghi, O. J. Miller, et al., "Dropletbased microfluidic systems for high-throughput single dna molecule isothermal amplification and analysis", Anal. Chem. 81, 4813-4821 (2009). http://dx.doi. org/10.1021/ac900403z

[93] T. Konry, I. Smolina, J. M. Yarmush, D. Irimia and M. L. Yarmush, "Ultrasensitive detection of lowabundance surface-marker protein using isothermal rolling circle amplification in a microfluidic nanoliter platform", Small 7, 395-400 (2011). http://dx.doi. org/10.1002/smll. 201001620

[94] A. Gansen, A. M. Herrick, I. K. Dimov, L. P. Lee and D. T. Chiu, "Digital LAMP in a sample self-digitization (SD) chip", Lab Chip 12, 2247-2254 (2012). http://dx.doi.org/10.1039/c2lc21247a

[95] B. M. Paegel, C. A. Emrich, G. J. Wedemayer, J. R. Scherer and R.A. Mathies, "High throughput DNA sequencing with a microfabricated 96-lane capillary array electrophoresis bioprocessor", Proc. Natl. Acad. Sci. USA 99, 574-579 (2002). http://dx.doi.org/10. 1073/pnas. 012608699

[96] L. M. Adleman, "Molecular computation of solutions to combinatorial problems", Science, New Series 266, 1021-1024 (1994). http://dx.doi.org/10.1126/ science. 7973651

[97] K. Sakamoto, H. Gouzu, K. Komiya, D. Kiga, S. Yokoyama, T. Yokomori and M. Hagiya, "Molecular computation by DNA hairpin formation", Science 288, 1223-1226 (2000). http://dx.doi.org/10.1126/ science. 288.5469.1223

[98] A. Gehani and J. Reif, "Micro flow bio-molecular computation", Biosystems 52, 197-216 (1999). http://dx. doi.org/10.1016/S0303-2647 (99)00048-9

[99] W. H. Grover and R. A. Mathies, "An integrated microfluidic processor for single nucleotide polymorphism-based DNA computing", Lab Chip 5, 1033-1040 (2005). http://dx.doi.org/10.1039/ b505840f

[100] H. N. Joensson and H. Andersson-Svahn, "Droplet microfluidics - a tool for protein engineering and analysis", Lab Chip 11, 4144-4147 (2011). http://dx.doi. org/10.1039/c1lc90102h 
[101] H. Salimi-Moosavi, P. Rathanaswami, S. Rajendran, M. Toupikov and J. Hill, "Rapid affinity measurement of protein-protein interactions in a microfluidic platform", Anal. Biochem. 401, 134-141 (2012). http:// dx.doi.org/10.1016/j.ab.2012.04.023

[102] B. Zheng, L. S. Roach and R. F. Ismagilov, "Screening of protein crystallization conditions on a microfluidic chip using nanoliter-size droplets", J. Am. Chem. Soc. 125, 11170-11171 (2003). http://dx.doi.org/ 10.1021/ja037166v

[103] L. Li, D. Mustafi, Q. Fu, V. Tereshko, D. L. Chen, J. D. Tice and R. F. Ismagilov, "Nanoliter microfluidic hybrid method for simultaneous screening and optimization validated with crystallization of membrane proteins", Proc. Natl. Acad. Sci. USA 103, 19243-19248 (2006). http://dx.doi.org/ 10.1073/pnas.0607502103

[104] J. W. Choi, D. K. Kang, H. Park, A. J. deMello and S. I. Chang, "High-throughput analysis of proteinprotein interactions in picoliter-volume droplets using fluorescence polarization", Anal. Chem. 84, 3849-3854 (2012). http://dx.doi.org/10.1021/ac300414g

[105] R. P. Hertzberg and A. J. Pope, "High-throughput screening: new technology for the 21st century", Curr.
Opin. Chem. Biol. 4, 445-451 (2000). http://dx.doi. org/10.1016/S1367-5931(00)00110-1

[106] X. Z. Niu, F. Gielen, J. B. Edel and A. J. deMello, "A microdroplet dilutor for high-throughput screening", Nature Chem. 3, 437-442 (2011). http://dx.doi.org/ 10.1038/nchem. 1046

[107] L. Granieri, J. C. Baret, A. D. Griffiths and C. A. Merten, "High-throughput screening of enzymes by retroviral display using droplet-based microfluidics", Chem. Biol. 17, 229-235 (2010). http://dx.doi.org/ 10.1016/j.chembiol.2010.02.011

[108] E. Brouzes, M. Medkova, N. Savenelli, D. Marran, M. Twardowski, J. B. Hutchison, J. M. Rothberg, D. R. Link, N. Perrimon and M. L. Samuels, "Droplet microfluidic technology for single-cell highthroughput screening", Proc. Natl. Acad. Sci. USA 106, 14195-14200 (2009). http://dx.doi.org/10. 1073/pnas. 0903542106

[109] V. Trivedi, A. Doshi, G. Kurup, E. Ereifej, P. Vandevord and A. S. Basu, "A modular approach for the generation, storage, mixing, and detection of droplet libraries for high throughput screening", Lab Chip 10, 2433-2442 (2010). http://dx.doi.org/10.1039/ c004768f 